Disponível em:

http://editora.unoesc.edu.br/index.php/race

Race, Joaçaba, v. 15, n. 1, p. 227-250, jan./abr. 2016

\title{
A INSERÇÃO DA SUSTENTABILIDADE NOS PROGRAMAS DE PÓS-GRADUACC̃̃O STRICTO SENSU EM ADMINISTRAÇÃO: A ÓTICA DOS ESPECIALISTAS
}

The insertion of sustainability on Strictu Sensu graduate in Administration Programs:

Expert's viewbint

Leandro Petarnella

E-mail: leandro_66@hotmail.com

Doutor em Administração pela Universidade Nove de Julho; Doutor em Educação pela Universidade de Sorocaba; Professor da Diretoria de Ciências Gerenciais da

Universidade de Sorocaba.

Flavio Hourneaux Junior

E-mail: flaviohjr@uol.com.br

Doutor e Mestre em Administração pela Universidade de São Paulo; Professor do Programa de Pós-Graduação em Administração da Universidade Nove de Julho; Professor

da Faculdade de Economia, Administração e Contabilidade da Universidade de São

Paulo.

Amélia Silveira

E-mail: ameliasilveira@gmail.com

Doutora em Ciências da Comunicação pela Universidade de São Paulo; Mestre em Administração pela Universidade Federal de Santa Catarina; Professora e Pesquisadora do Programa de Pós-Graduação em Administração e Ciências Contábeis da

Universidade Nove de Julho.

Endereço para correspondência: Avenida Professor Luiz Ignácio Anhaia Mello, 1363, Vila Prudente, 03155-000, São Paulo, São Paulo, Brasil.

Artigo recebido em 08 de setembro de 2015. Aceito em 18 de novembro de 2015. 
Resumo

Diante da necessidade de se pensar um novo paradigma social, ou seja, a sustentabilidade, a partir dos espaços geradores e disseminadores do conhecimento, neste trabalho objetivou analisar como essa temática da sustentabilidade vem sendo considerada nos Programas de Pós-graduação Stricto Sensu em Administração, no Brasil. Para tanto, parte de uma pesquisa de natureza quantitativa que contou com a participação de 40 pesquisadores pertencentes aos grupos de pesquisas certificados pelo Conselho Nacional de Pesquisa Científica e Tecnológica (CNPQ) e atuantes nos programas estudados, aqui entendidos como especialistas. Os resultados apontaram diversidade no perfil dos responsáveis pelos temas de sustentabilidade e diferenças em relação à forma como a sustentabilidade vem sendo abordada nesses programas objetos de estudo; revelaram, ainda, a necessidade de reformulação dos currículos desses programas sob a ótica do novo paradigma esperado para o ordenamento social.

Palavras-chave: Ensino em Administração. Pós-Graduação em Administração. Sustentabilidade.

\title{
The insertion of sustainability on Strictu Sensu graduate in Administration Programs: Expert's viewbint
}

\begin{abstract}
There is a need to consider a new social paradigm, namely, sustainability, from the generators and disseminators of knowledge spaces. This study aimed to analyze how the issue of sustainability has been considered in Strictu Sensu Graduate in Administration Program in Brazil. The analysis is based on a quantitative survey that involved the participation of 40 researchers from certified research groups at Conselho Nacional de Pesquisa Científica e Tecnológica (CNPQ) and active in the programs. These researchers are recognized here as experts. The results showed that there is diversity in the profile of those responsible for sustainability issues. It also pointed that there are differences regarding the way sustainability has been approached in the analyzed programs. They also reveal the need to restructure the curriculum of these programs from the perspective of the new paradigm expected for the social order.

Keywords: Administration Education Administration. Graduate in Business Administration. Sustainability.

\section{INTRODUÇÃO}

A sustentabilidade é o desafio da contemporaneidade. É recorrente o entendimento de que se trata de uma questão que deve ser revista e refletida por todos, uma vez que pressupõe novos rumos para o desenvolvimento social, assim como o estabelecimento de bases comparativas de desenvolvimento.
\end{abstract}


Para se estabelecerem os novos rumos e as respectivas bases, faz-se necessária a construção de valores éticos e morais, os quais dependem, necessariamente, da formação educacional de determinada sociedade. Nesse ponto emerge a importância e a justificativa deste estudo: entender como as instituições de ensino superior vêm produzindo e disseminando o conhecimento na área de administração, considerando que essas organizações educacionais são responsáveis pela formação dos sujeitos que possuem como desafio compreender e relacionar as questões éticas e morais a partir da inter-relação das questões econômicas, sociais e ambientais. Em decorrência, o entendimento de como os sujeitos atuam nos espaços geradores e disseminadores do conhecimento - no caso, os professores dos Programas de Pós-Graduação Stricto Sensu em Administração - se firma como condição sine qua non para a verificação das formas como os valores sociais vêm sendo construídos quanto à sustentabilidade.

O foco nos Programas de Pós-Graduação Stricto Sensu em Administração se justifica pelas possibilidades de entendimento das formas pelas quais o homem enxerga a realidade e a transmite por meio da educação. Entende-se que são nos Programas Stricto Sensu que se mobilizam maiores esforços, por parte das instituições educacionais e de seus atores, em torno de um exercício que pode transformar ou construir novas representações dessa realidade. Assim, são os referidos Programas que permitem a ultrapassagem do campo dado pela ciência, por meio da pesquisa, para se estabelecer na ordem de uma racionalidade que possa ser estruturada no cotidiano social, a partir do ensino.

A estruturação de um novo paradigma social inserido nos espaços geradores e disseminadores do conhecimento ainda é recente no Brasil. Ao refletir sobre a sustentabilidade como um novo paradigma social, percebe-se que o desafio de se produzir conhecimento acerca desse assunto se firma como sendo tão importante quanto necessário. Em decorrência disso, muito embora haja uma série de estudos que tratam da inserção da sustentabilidade nos cursos de graduação, como, por exemplo, as pesquisas de Barth et al. (2007), Brundiers, Wiek e Redman (2009) e Leal Filho (2011) e, mais especificamente, nos cursos de graduação em Administração, como os trabalhos de Adomssent et al (2014), Gonçalvez-Dias, Beloque e Herrera (2011) e Jacobi, Raufflet e Arruda (2011), pesquisas que investiguem esse tema, no nível de pós-graduação, ainda são raras. Aliás, em específico, no Brasil, salvo poucas exceções, como os trabalhos de Canhada e Bulgacov (2011), Pereira et al. (2002), Petarnella e Silveira (2013, 2014) e de Petarnella, Hourneaux Junior e Silveira (2014), pode-se afirmar que o tema ainda é pouco explorado pelas academias. 
Com esse entendimento, a questão norteadora desta pesquisa pôde ser assim enunciada: Como a sustentabilidade se insere nos Programas de Pós-Graduação Stricto Sensu em Administração no Brasil? Para responder a essa questão de pesquisa, optou-se investigá-la por meio da atuação docente, com a participação de especialistas em sustentabilidade, com o devido registro em Grupos de Pesquisa no Conselho Nacional de Desenvolvimento Científico e Tecnológico (CNPq).

A proposta de se tratar esse tema baseia-se na necessidade de se entenderem as bases fundantes do ensino e da pesquisa sobre a sustentabilidade nos espaços que orientam suas práticas, por meio do ensino, da pesquisa e da extensão, ou seja, no ambiente das Instituições de Ensino Superior (IES). Perceber e refletir sobre o que vem sendo construído enquanto conhecimento a respeito desse assunto e como ele está inserido nos Programas de Pós-Graduação Stricto Sensu em Administração desvela e justifica a relevância deste trabalho.

Vale ressaltar que, sendo a sustentabilidade a tentativa de (re)ordenamento da dinâmica social instituída a partir da Segunda Revolução Industrial, sua base epistêmica não se pauta em estudos orientados para essa finalidade. Aliás, nesse ponto encontra-se o desafio proposto por esse paradigma, já que são justamente os acordos e tratados internacionais que orientam o assunto. Aqui cabe destacar o tratado de 1962, no qual a Conferência da Organização das Nações Unidas (ONU) sobre o Meio Ambiente buscou minimizar as diferenças de desenvolvimento a partir do crescimento zero proposto pelo Clube de Roma. Ainda, a conferência de Estocolmo (1972), a declaração de Cocoyok (1974), o Programa Internacional de Educação Ambiental (1975), o relatório de Dag-Hammarskjold, a Conferência Mundial de Desenvolvimento e Meio Ambiente, a Rio 92 (1992), bem como a Rio+10 (2002) e a Rio+20 (2012) alicerçaram o delineamento dos caminhos apontados e percorridos na tentativa de se estabelecer uma nova ordem social. Assim, percebe-se que as discussões das últimas conferências orientadas para a sustentabilidade desvelaram esforços políticos e governamentais, entre tantos discursos, para a incorporação de novos valores sociais. Pouco a pouco o desenvolvimento sustentável parece ser um destino inevitável para o qual todos devem convergir.

Baseando-se nos tratados e acordos políticos governamentais, autores como Brüseke (1993), Vieira (1992) e Kitamura (1994) pesquisaram sobre as possibilidades de efetivação dos respectivos acordos. Becker (1997), por sua vez, buscou entender quais são as possibilidades emergentes da orientação tecnológica, de investimentos e de mudanças institucionais, a fim de se traçarem novas rotas para o alcance do desenvolvimento sustentável. 
Para descrever o desenvolvimento da pesquisa realizada, o presente artigo está estruturado a partir desta introdução. Apresenta, em seguida, a pós-graduação stricto sensu no Brasil e a sustentabilidade, construindo o assunto. O método e as técnicas de pesquisa adotadas estão definidos na terceira seção. Os resultados da pesquisa de campo oportunizaram ampliar o assunto de interesse; ao término são apontadas as considerações finais, as limitações do estudo e as sugestões para futuras pesquisas.

\section{SUSTENTABILIDADE: UMA VISÃO GERAL}

Para se pensar uma administração orientada a partir da sustentabilidade, faz-se necessário um redimensionamento de seus propósitos, o que implica um descolamento dos paradigmas que a originaram. Nesse sentido, conforme afirma Abramovay (2012), uma nova forma de organização que vislumbre estratégias alternativas de transição para uma nova ordem social pode ser decisiva a partir das “[...] influências que elas exercem, não só nas políticas públicas, mas, sobretudo, nas forças sociais diversas que interferem de forma cada vez mais explícita na definição dos sistemas administrativos.” (ABRAMOVAY, 2012, p. 17).

Para Hart e Milstein (2003), a sustentabilidade é um conceito multidimensional, que não pode ser simplesmente direcionado a cada ação da organização. Além disso, uma vez que elas são detentoras de grande poder econômico, social e político, as organizações podem influenciar, em larga escala, os contextos em que atuam (HART, 2007).

Sachs (1993) corrobora o escopo amplo da sustentabilidade e aponta que ela poderia ser categorizada em cinco diferentes dimensões: Social, Econômica, Ecológica, Espacial/ Geográfica e Cultural, reforçando o conceito de multidimensionalidade e de complexidade do tema. Já na visão de Viederman (1994), a sustentabilidade pode ser definida como um "[...] processo participativo que cria e busca uma visão da comunidade que respeita e faz uso prudente de todos os seus recursos - naturais, humanos, criados pelos humanos, sociais, culturais, científicos e outros.”

Apesar de ser ainda dominante na formação do administrador o domínio da dimensão econômica, conforme enfatizam Gomes e Moretti (2007), trabalhos como os de Carroll, (1999), Pirsch, Gupta e Gra (2007) e Moretti e Figueiredo (2007) revelam que as questões econômicas, ambientais e sociais são inter-relacionadas, principalmente, a partir das dimensões éticas e morais. Em decorrência disso, as ações do administrador para a realização da sustentabilidade dependerão ainda dos valores éticos e morais que se construam nessa trajetória. 
Procurando desvelar como essa temática se insere em um espaço que, no caso brasileiro, ainda se encontra em processo de consolidação e de constituição de sua própria identidade, a pós-graduação stricto sensu, no Brasil, e a relação com o estudo da sustentabilidade.

\subsection{A PÓS-GRADUAÇÃO STRICTO SENSU NO BRASIL E A SUSTENTABILIDADE}

Com base no artigo n. 71, do Estatuto da Universidade do Brasil, firmado em 1940, iniciaram-se as articulações entre o Brasil e os Estados Unidos da América, para a oferta da Pós-Graduação brasileira. Em 1951, por meio do Decreto n. 29.741, foi criada a Comissão Nacional de Aperfeiçoamento de Pessoal de Nível Superior (atual Coordenação de Aperfeiçoamento de Pessoal de Nível Superior - CAPES), cujo principal objetivo foi o atendimento às ações desenvolvimentistas do País. Essa Comissão deveria auxiliar na construção de um país desenvolvido e independente e, por isso, deveria formar especialistas e pesquisadores nos mais diversos ramos de atividade (COORDENAÇÃO DE APERFEIÇOAMENTO DE PESSOAL DE NÍVEL SUPERIOR, 2013).

A formação de especialistas em variadas áreas começou a gerar resultados, efetivamente, a partir da década de 1960, principalmente por meio da parceria do Governo brasileiro com a Fundação Ford. Nesse momento, iniciou-se o movimento de estruturação da Pós-Graduação no Brasil (SANTOS, 2003), entretanto, de maneira ainda incipiente e difusa. Foi somente em 1965, novamente subordinados ao Ministério da Educação e Cultura (MEC), que os cursos de Pós-Graduação Stricto Sensu começam a ser regulamentados.

Em 1995, já em fase de consolidação, a Pós-Graduação brasileira ultrapassou 1.000 mestrados e 600 doutorados, somando, nesses cursos, mais de 60 mil alunos (COORDENAÇÃO DE APERFEIÇOAMENTO DE PESSOAL DE NÍVEL SUPERIOR, 2013).

Dando especificidade à administração, segundo Bertero, Caldas e Wood Júnior (1999, p. 4):

A área de administração encontra-se presente na Pós-Graduação Stricto Sensu desde os seus primeiros passos. Foi em meados dos anos sessenta e início da década seguinte que os programas em administração surgiram no Rio de Janeiro, São Paulo, Minas Gerais, Rio Grande do Sul e Paraíba. 
De acordo com Lima (2000), “[...] os programas de doutorado tem promovido o desenvolvimento de grupos ou centros, denominações de marca de especializações internas aos programas, com denominações que indicam concentração de pesquisas e produção de técnicas de intervenção no mundo empresarial”. Entretanto, segundo Lima (2000), diante das críticas de Hamburguer (1980) e Bertero, Caldas e Wood Júnior (1997), surgem, na atualidade, novas demandas para os Programas de Pós-Graduação Stricto Sensu em Administração.

Tratando-se da sustentabilidade, sua inserção nos Programas de Pós-Graduação Stricto Sensu em Administração se tornou uma questão central em 2012.

Uma exigência legal, ratificada pela Resolução n. 2, do Conselho Nacional de Educação (CNE), que aprovou o parecer CNE/CP n. 8, de 06 de março de 2012, homologado por despacho do Ministro de Estado da Educação, estabeleceu que

[...] a Educação Ambiental é componente integrante, essencial e permanente da Educação Nacional, devendo estar presente, de forma articulada, nos níveis e modalidades da Educação Básica e da Educação Superior, para isso devendo as instituições de ensino promovê-la integradamente nos seus projetos institucionais e pedagógicos.

Reafirmando a necessidade, no artigo n. 8, parágrafo único, de que nos cursos e programas de Pós-Graduação fica facultada, inclusive, a criação de componentes específicos para esse fim. A rigor, o Parecer n. 8, do CNE/CP (2012), instruiu que a questão ambiental, traduzida em um esforço, para a mudança dos valores éticos e morais da sociedade deverá ser tratada na Pós-Graduação, se não como tema transversal, como disciplina curricular, evidenciando a necessidade da inserção da sustentabilidade nos respectivos Programas. Percebe-se, portanto, que mesmo tal exigência supriria apenas o foco ambiental dentro da temática mais ampla de sustentabilidade.

Dessa forma, diante da legalidade da medida, a sustentabilidade deve ser considerada temática nos Programas de Pós-Graduação Stricto Sensu em Administração no Brasil. O interesse em analisar como o tema sustentabilidade se insere nesses Programas norteia o delineamento metodológico deste estudo.

\section{MÉTODOS E TÉCNICAS DE PESQUISA}

Em razão da necessidade de se ampliar o conhecimento na temática da pesquisa, uma vez que são poucos os trabalhos já realizados com esse fim, este estudo foi definido como descritivo, quando os estudos “[...] destinam-se a descrever as ca- 
racterísticas de determinada situação.” (BOYD JÚNIOR; WESTFALL, 1979, p. 68). Para isso, fez-se uso de uma abordagem quantitativa, pois se utilizou uma "[...] metodologia de pesquisa que procura quantificar os dados e, geralmente, aplica alguma forma de análise estatística.” (MALHOTRA, 2006, p. 154). O raciocínio foi dedutivo.

A pesquisa realizada foi do tipo survey, que consiste em uma ferramenta de “autoreporte” de dados factuais ou opiniões, sendo possível aplicá-la a um grupo homogêneo, com, pelo menos, uma característica comum (FLYNN et al., 1990). Assim, optou-se pela análise de um grupo de pessoas que, aqui denominadas de especialistas, possuem características gerais comuns, homogêneas e, de alguma maneira, aderência à temática tratada. Dessa forma, para integrar esse grupo e ser considerado especialista, pertencendo à amostra selecionada para a pesquisa, o participante deveria: possuir produção científica na área da sustentabilidade e/ou, ser líder de grupo de pesquisa vinculado à grande área de Administração, certificado pelo CNPq, e lecionar na Pós-Graduação Stricto Sensu, em Administração.

Nos registros do CNPQ existiam, por ocasião do estudo, 231 grupos de pesquisas vinculados à área da Administração e que tratam da sustentabilidade. Somados à relação nominal dos líderes desses grupos, selecionados como respondentes, em princípio, foram selecionados, ainda, 63 sujeitos sociais que possuíam produção científica em sustentabilidade. Entretanto, verificando sua compatibilidade dos líderes dos grupos de pesquisa em sustentabilidade com sua atuação em Programas de Pós-Graduação Stricto Sensu em Administração, bem como de autores em sustentabilidade com atuação atual nesses mesmos Programas, o número reduziu, verdadeiramente, passando a ser de 72 sujeitos sociais especialistas.

A seguir, foi elaborado um instrumento de coleta de dados que deveria ser respondido pelos especialistas identificados. O questionário foi elaborado em formato eletrônico, sendo enviado com uma carta convite via Internet e para o correio eletrônico dos especialistas identificados. Na sequência, foram enviados convites específicos para esses especialistas, de forma a assegurar sua participação voluntária na pesquisa. Dessa forma, apesar de a pesquisa de campo se caracterizar como quantitativa quanto à coleta dos dados, a amostra foi definida de forma intencional, baseada em critérios de qualidade, pois segue o critério determinado pelo pesquisador (COOPER; SCHINDLER, 2003); é não probabilística, com característica “[...] arbitrária (não aleatória) e subjetiva” (COOPER; SCHINDLER, 2003, p. 152) e de participação voluntária (SAUNDERS; LEWIS; THORNHILL, 2007, p. 233).

A coleta de dados foi realizada entre agosto e outubro de 2013. Para a análise dos dados, além das técnicas de análise estatística descritivas, foram utilizadas tam- 
bém as técnicas estatísticas para a própria validação do instrumento de pesquisa e para a identificação de diferenças quanto aos aspectos avaliados pelo instrumento.

\subsection{O INSTRUMENTO DE COLETA DE DADOS}

Como complemento às informações necessárias para atender aos propósitos deste estudo, foi elaborado um instrumento para medida quantitativa dos dados da amostra, a partir do instrumento original de Miranda e Moresi (2010). Esse instrumento foi destinado a mensurar o conhecimento relacionado à gestão do conhecimento. A utilização desse questionário se justifica, posto que se pretendeu mensurar o conhecimento relacionado com a sustentabilidade na pós-graduação em administração brasileira, cujo processo se iniciaria - ou dependeria - dos responsáveis pelos cursos e disciplinas no tema em questão.

Desse modo, ajustado para o contexto deste trabalho, o instrumento foi composto por 12 itens associados a uma escala de reconhecimento do conhecimento do tipo Likert, de cinco pontos, com escores variados correspondentes a "Não Tem Nenhum Conhecimento”, “Tem Pouco Conhecimento”, “Tem Conhecimento Moderado”, “Tem Muito Conhecimento” e “Tem Total Conhecimento” (MIRANDA; MORESI, 2010). A relação das questões foi apresentada no Quadro 1. O questionário contou com 12 questões fechadas e outras cinco abertas e foi enviado a todos os integrantes da amostra, após um pré-teste realizado com 10 professores de pós-graduação de uma universidade da Cidade de São Paulo, SP, que não faziam parte da pesquisa.

De toda a amostra, obteve-se o retorno de 72 respondentes, mas 40 foram considerados válidos para esta pesquisa.

Os itens considerados no instrumento de coleta de dados estão relacionados a seguir.

Quadro 1 - Instrumento de coleta de dados

\begin{tabular}{|l|l|}
\hline Código & Questão \\
\hline P_01 & $\begin{array}{l}\text { Como você avalia a preocupação de seu Programa de Pós-Graduação com a sustentabilida- } \\
\text { de? }\end{array}$ \\
\hline P_02 & Como você avalia a preocupação de seus alunos com a sustentabilidade? \\
\hline P_03 & $\begin{array}{l}\text { Como você avalia o entendimento do que venha a ser a sustentabilidade, por parte de seu } \\
\text { programa? }\end{array}$ \\
\hline P_04 & $\begin{array}{l}\text { Qual é a preocupação que você possui em relação às questões relacionadas à sustentabilida- } \\
\text { de? }\end{array}$ \\
\hline P_05 & Como você avalia o seu entendimento do que vem a ser a sustentabilidade? \\
\hline P_06 & $\begin{array}{l}\text { Como você avalia a preocupação de seu Programa de Pós-Graduação com a inserção do } \\
\text { tema sustentabilidade nas disciplinas ministradas? }\end{array}$ \\
\hline
\end{tabular}




\begin{tabular}{|l|l|}
\hline P_07 & $\begin{array}{l}\text { Como você avalia o tratamento dado à sustentabilidade no que diz respeito à abordagem da } \\
\text { temática em sala de aula? }\end{array}$ \\
\hline P_08 & $\begin{array}{l}\text { De acordo com a sua percepção, as disciplinas oferecidas pelo Programa de Pós-Graduação } \\
\text { vêm respondendo às novas demandas do mercado, no que diz respeito a questões ambientais } \\
\text { e sociais, de maneira eficiente? }\end{array}$ \\
\hline P_09 & $\begin{array}{l}\text { Como você avalia o entendimento do que vem a ser a sustentabilidade por parte de seus } \\
\text { alunos? }\end{array}$ \\
\hline P_10 & $\begin{array}{l}\text { Como você avalia a importância de seu Programa de Pós-Graduação no desenvolvimento e } \\
\text { disseminação de atividades sustentáveis? }\end{array}$ \\
\hline P_11 & $\begin{array}{l}\text { De acordo com a sua percepção, seu Programa de Pós-Graduação se esforça para criar nos } \\
\text { colaboradores a capacidade de gerar valor sustentável para a sociedade em geral? }\end{array}$ \\
\hline P_12 & $\begin{array}{l}\text { Como você avalia as oportunidades que o seu Programa de Pós-Graduação lhe oferece para } \\
\text { desenvolver atividades a partir de ações sustentáveis? }\end{array}$ \\
\hline
\end{tabular}

Fonte: os autores.

Assim, as 12 questões compuseram o instrumento de coleta de dados utilizado na pesquisa. $\mathrm{O}$ que se fez a seguir foi verificar a confiabilidade do instrumento por meio do teste de Alpha de Cronbach, para seus 12 itens, evidenciando, dessa forma, que a escala é consistente (FIELD, 2009). Os resultados dessa análise podem ser visualizados na Tabela 1.

Tabela 1 - Confiabilidade do instrumento de coleta de dados

\begin{tabular}{lll}
\hline Alpha de Cronbach & Alpha de Cronbach Padronizado & Número de itens \\
\hline ,919 &, 905 & 12 \\
\hline
\end{tabular}

Fonte: os autores.

Para verificar a validade do instrumento de pesquisa, realizou-se o teste de Kaiser-Meyer-Olkin (KMO), cujo objetivo é a verificação da adequação da escala. Para tanto, seus resultados devem ser superiores a 0,5 para serem aceitos visto que a adequação ideal deve considerar valores acima de 0,7, conforme delineia Field (2009). Entretanto, esse resultado deve estar associado a um nível de significância menor ou igual a 0,05 para ser considerada boa a consistência interna para a análise fatorial. Os resultados apresentados aqui também estão associados ao teste de esfericidade de Bartlett, como apresentado na Tabela 2.

Tabela 2 - Validade do instrumento de coleta de dados

\begin{tabular}{lll}
\hline Kaiser-Meyer-Olkin Measure of Sampling Adequacy & ,808 \\
\hline Bartlett's Test of Sphericity & Approx. Chi-Square & 377,38 \\
& Df & 66 \\
& Sig. &, 000 \\
\hline
\end{tabular}

Fonte: os autores. 


\section{APRESENTAÇÃO E DISCUSSÃO DOS RESULTADOS}

Os dados foram coletados em uma amostra formada por 40 professores especialistas em sustentabilidade, atuantes no Brasil, distribuídos em suas diversas regiões.

\subsection{CARACTERÍSTICAS DA AMOSTRA}

O perfil geral dos 40 participantes consta na Tabela 3.

Tabela 3 - Perfil dos participantes da pesquisa

(continua)

\begin{tabular}{|c|c|c|c|}
\hline Variáveis & Categoria & Quantidade & Percentual (\%) \\
\hline \multirow{2}{*}{ Sexo } & Masculino & 25 & 62,5 \\
\hline & Feminino & 15 & 37,5 \\
\hline \multirow{5}{*}{$\begin{array}{l}\text { Tempo de atuação em Pós } \\
\text { Graduação Stricto Sensu }\end{array}$} & 1 a 4 meses & 10 & 25 \\
\hline & 5 a 9 meses & 11 & 27,5 \\
\hline & 10 a 14 meses & 10 & 25 \\
\hline & 15 a 18 meses & 6 & 15 \\
\hline & 19 a 24 meses & 3 & 7,5 \\
\hline \multirow{5}{*}{ Região } & Norte & 2 & 5,0 \\
\hline & Sudeste & 26 & 65 \\
\hline & Sul & 8 & 20 \\
\hline & Centro-Oeste & 2 & 5,0 \\
\hline & Nordeste & 2 & 5,0 \\
\hline \multirow{12}{*}{ Estado } & São Paulo & 19 & 47,5 \\
\hline & Rio de Janeiro & 4 & 10 \\
\hline & Minas Gerais & 3 & 7,5 \\
\hline & Paraná & 3 & 7,5 \\
\hline & Rio Grande do Sul & 3 & 7,5 \\
\hline & Santa Catarina & 2 & 5,0 \\
\hline & Amazônia & 1 & 2,5 \\
\hline & Rondônia & 1 & 2,5 \\
\hline & Mato Grosso do Sul & 1 & 2,5 \\
\hline & Mato Grosso & 1 & 2,5 \\
\hline & Paraíba & 1 & 2,5 \\
\hline & Pernambuco & 1 & 2,5 \\
\hline
\end{tabular}


(conclusão)

\begin{tabular}{llll}
\hline Variáveis & Categoria & Quantidade & Percentual (\%) \\
\hline & Administração & 10 & 25 \\
& Educação & 6 & 15 \\
Ciências Sociais & 3 & 7,5 \\
& Engenharia & 5 & 12,5 \\
& Agronegócios & 2 & 5,0 \\
& Ciências & 1 & 2,5 \\
Formação & Ciências Sociais & 1 & 2,5 \\
& Ciências Florestais & 1 & 2,5 \\
& Ciências e Geografia Hu- & 1 & 2,5 \\
& mana & & \\
& Economia & 2 & 5,0 \\
& Geografia & 1 & 2,5 \\
& Geologia Dinâmica & 2 & 5,0 \\
& Medicina & 1 & 2,5 \\
& Política e Tecnologia & 1 & 2,5 \\
Disciplinas ministradas & Psicologia & 1 & 2,5 \\
& Serviço Social & 1 & 2,5 \\
& Sociologia & 1 & 2,5 \\
\hline Variáveis & Categoria & Quas & Percentual (\%) \\
\hline & & 11 & 40,0 \\
& Tpenas uma & 27,5 \\
& & 32,5 \\
\hline
\end{tabular}

Fonte: os autores.

Percebe-se que o predomínio é de participantes do sexo masculino, com tempo de titulação heterogênea e formação diversificada, com concentração na Região Sudeste, principalmente em São Paulo, SP. Da amostra, 25\% têm formação em Administração, havendo variação na quantidade de disciplinas que lecionam em suas devidas instituições, de uma a três.

Além disso, foram levantados os vínculos dos respondentes nos Programas de pós-graduação. Por meio das respostas, percebe-se que, dos especialistas entrevistados, 18,42\% lecionam nos mestrados acadêmicos, exclusivamente, 32,89\%, nos mestrados profissionais, exclusivamente, e 5,26\%, nos programas de doutorado, exclusivamente. Além disso, 43,42\% lecionam em programas de mestrados e doutorados. 


\subsection{VALIDAÇÃO DO INSTRUMENTO DE COLETA DE DADOS}

Tratando, agora, dos sujeitos válidos, a partir da tabulação das respostas desses sujeitos, foi realizada uma análise fatorial exploratória da escala, com rotação Varimax. Observou-se a adequação do modelo, composto por apenas um fator em seus 12 itens, ao modelo original de Miranda e Moresi (2010). Observou-se, também, que não foi necessária a exclusão de nenhum de seus itens, por apresentarem valores consistentes, aferidos com o teste de Alpha de Cronbach, conforme mostrado na Tabela 4.

Tabela 4 - Validade do instrumento de coleta de dados

\begin{tabular}{lll}
\hline Alpha de Cronbach & Alpha de Cronbach Padronizado & Número de itens \\
\hline ,914 &, 900 & 12 \\
\hline
\end{tabular}

Fonte: os autores.

Outra aferição considerada relevante para a validação do instrumento de pesquisa corresponde ao valor do teste Kaiser-Meyer-Olkin (KMO), igual a 0,784, que demonstra, segundo Field (2009), boa consistência interna para a análise fatorial dado que seu nível de significância é menor do que 0,0001, aferido no teste de esfericidade de Bartlett, como apresentado na Tabela 5.

Tabela 5 - Validade do instrumento de coleta de dados

\begin{tabular}{llc}
\hline \multicolumn{2}{l}{ Kaiser-Meyer-Olkin Measure of Sampling Adequacy } & \multirow{2}{*}{, 784} \\
\hline Bartlett's Test of Sphericity & Approx. Chi-Square & 380,635 \\
& Df & 66 \\
& Sig. &, 000 \\
\hline
\end{tabular}

Fonte: os autores.

\subsection{ESTATÍSTICA DESCRITIVA}

Na análise descritiva das respostas apuradas, percebe-se que a média amostral dos itens não apresentou diferenças significativas quando comparada aos elementos do mesmo grupo, conforme apresentado na Tabela 6.

Tabela 6 - Estatística descritiva para as respostas obtidas

(continua)

\begin{tabular}{lllllll}
\hline Item & N. & Média & Desvio padrão & Mediana & Valor mínimo & Valor máximo \\
\hline P_01 & 40 & 3,55 & 1,13 & 3 & $\mathbf{1}$ & 5 \\
P_02 & 40 & $\mathbf{3 , 8 5}$ & 0,83 & 4 & 2 & 5 \\
P_03 & 40 & 3,65 & 1,00 & 4 & 2 & 5 \\
P_06 & 40 & 3,50 & 1,26 & 3,50 & $\mathbf{1}$ & 5
\end{tabular}


(conclusão)

\begin{tabular}{lllllll}
\hline Item & N. & Média & Desvio padrão & Mediana & Valor mínimo & Valor máximo \\
\hline P_07 & 40 & 3,65 & 1,14 & 4 & 2 & 5 \\
P_08 & 40 & 3,42 & 1,17 & 3 & 2 & 5 \\
P_09 & 40 & 3,62 & 1,03 & 4 & $\mathbf{1}$ & 5 \\
P_10 & 40 & 3,65 & 1,21 & 4 & $\mathbf{1}$ & 5 \\
P_11 & 40 & 3,52 & 1,13 & 3 & 2 & 5 \\
P_12 & 40 & 3,65 & 0,98 & 4 & 2 & 5 \\
\hline
\end{tabular}

Fonte: os autores.

Como se pode observar na Tabela 6, a variável P_02 (Como você avalia a preocupação de seus alunos com a sustentabilidade?) possui a média mais alta em relação a todas as demais, reforçando a ideia de que os alunos são uma fonte de interesse e de pressão para o desenvolvimento da temática nos Programas. Por outro lado, a variável P_08 (De acordo com a sua percepção, as disciplinas oferecidas pelo Programa de Pós-Graduação vêm respondendo às novas demandas do mercado, no que diz respeito a questões ambientais e sociais, de maneira eficiente?) apresenta a média mais baixa. Ou seja, de um lado há uma forte demanda e de outro há uma séria dificuldade em se responder e atender essa demanda.

Todas as demais variáveis apresentam notas mínimas iguais a 2, o que também pode ser um sinal de que ainda se trata de uma temática incipiente, considerando-se o entendimento sobre a sustentabilidade (variáveis P_03 Como você avalia o entendimento do que vem a ser a sustentabilidade, por parte de seu programa? e P_05 Como você avalia o seu entendimento do que vem a ser a sustentabilidade?) e como ela é tratada em sala de aula (P_07 Como você avalia o tratamento dado à sustentabilidade no que diz respeito à abordagem da temática em sala de aula?), a preocupação pessoal com o tema (P_04 Qual é a preocupação que você possui em relação às questões relacionadas à sustentabilidade), o esforço para fomentar a sustentabilidade nos colaboradores do Programa (P_11 De acordo com a sua percepção, seu Programa de Pós-Graduação se esforça para criar nos colaboradores a capacidade de gerar valor sustentável para a sociedade em geral?) e, finalmente, as possibilidades de se praticar a sustentabilidade (P_12 Como você avalia as oportunidades que o seu Programa de Pós-Graduação lhe oferece para desenvolver atividades a partir de ações sustentáveis?).

Observa-se, também, que as variáveis P_01 (Como você avalia a preocupação de seu Programa de Pós-Graduação com a sustentabilidade?), P_06 (Como você avalia a preocupação de seu Programa de Pós-Graduação com a inserção do tema 
sustentabilidade nas disciplinas ministradas?), P_09 (Como você avalia o entendimento do que vem a ser a sustentabilidade por parte de seus alunos?) e P_10 (Como você avalia a importância de seu Programa de Pós-Graduação no desenvolvimento e disseminação de atividades sustentáveis?) apresentaram valores mínimos (iguais a 1), o que implica dizer que os respectivos respondentes admitem estar em uma situação crítica em relação ao tema que desenvolvem em seus programas.

\subsection{TESTE ESTATÍSTICO}

Na comparação das médias das respostas obtidas dos participantes, a fim de rejeitar a hipótese nula de que são iguais, apurou-se na análise da variância um p-value $<0,05$, o que leva à rejeição da hipótese nula de igualdade das médias apuradas com o instrumento, o que significa que as médias apuradas entre as questões não são iguais, pois existem diferenças significativas nos níveis de resposta dos indivíduos. Conclui-se, assim, que os resultados da Anova indicaram diferenças significativas, como se observa na Tabela 7.

Ao final, com a análise das comunalidades obtidas, observou-se a proporção da variância obtida explicada por seus componentes principais, em que se apurou que os itens P_4 e P_5 apresentaram valores abaixo do esperado (0,038 e 0,002, respectivamente). Assim, percebe-se que, uma vez que os itens não explicam totalmente nenhuma variância da variável, optou-se por sua exclusão nos demais testes e análises, seguindo-se o critério de Field (2009), que considera que variáveis com valores baixos têm pouco em comum com as demais e não são explicadas por seus componentes.

Tabela 7 - Teste Anova com teste de Tukey para não aditividade

\begin{tabular}{|c|c|c|c|c|c|c|c|}
\hline & & & $\begin{array}{l}\text { Soma dos } \\
\text { Quadrados }\end{array}$ & $\mathrm{DF}$ & $\begin{array}{l}\text { Quadrados } \\
\text { Médios }\end{array}$ & $\mathrm{F}$ & Sig \\
\hline Entre indivíduos & & & 252,731 & 39 & 6,480 & & \\
\hline \multirow[t]{5}{*}{ Com indivíduo } & Entre os Itens & & 74,323 & 11 & 6,757 & 12,073 &, 000 \\
\hline & Residual & $\begin{array}{l}\text { Nonadditi- } \\
\text { vity }\end{array}$ & $44,272^{\mathrm{a}}$ & 1 & 44,272 & 96,763 & ,000 \\
\hline & & Balance & 195,822 & 428 & & & \\
\hline & & Total & 240,094 & 429 & & & \\
\hline & Total & & 314,417 & 440 & & & \\
\hline Total & & & 567,148 & 479 & & & \\
\hline \multicolumn{8}{|l|}{ Média Geral = } \\
\hline 3,7771 & & & & & & & \\
\hline
\end{tabular}

Fonte: os autores.

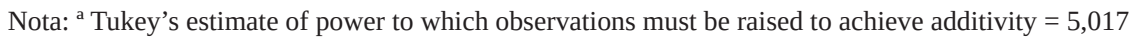




\section{DISCUSSÃO DOS RESULTADOS DE PESQUISA}

Por meio dos resultados obtidos das análises das respostas extraídas dos questionários aplicados aos especialistas, percebe-se que o grupo que atua na Pós-Graduação Stricto Sensu em Administração é bastante heterogêneo em termos de características demográficas e também em formação acadêmica. Isso implica dizer, a rigor, que se desvela, por meio dessa heterogeneidade, a tentativa de se tratar a sustentabilidade sob diversos vieses teóricos e/ou metodológicos, indicando, dessa forma, que o ensino da sustentabilidade é, ainda, orientado a partir do conhecimento e/ou noção que cada especialista possui sobre a temática.

Também por meio do instrumento de coleta de dados, percebe-se que há uma heterogeneidade nos quesitos definidos para avaliar a inserção da sustentabilidade nos programas. Aspectos relevantes, como a preocupação do Programa com a sustentabilidade, a preocupação de seus alunos com a sustentabilidade, o entendimento do que vem a ser a sustentabilidade, a preocupação do Programa com a inserção do tema sustentabilidade nas disciplinas ministradas, o tratamento dado à sustentabilidade no que diz respeito à abordagem da temática em sala de aula, as disciplinas oferecidas pelo Programa como resposta a novas demandas do mercado, o entendimento do que vem a ser a sustentabilidade por parte dos alunos, a importância do Programa no desenvolvimento e disseminação de atividades sustentáveis, o esforço para criar nos colaboradores a capacidade de gerar valor sustentável para a sociedade em geral, e as oportunidades que o Programa oferece ao professor para desenvolver atividades a partir de ações sustentáveis foram identificados como heterogêneos pelos respondentes.

Em outras palavras, percebe-se que o exposto pode ter relação com a ausência de uma matriz consolidada sobre a temática que se traduza em um conhecimento e em práticas que sejam disseminadas efetivamente. Se a sustentabilidade não possui contornos definidos, o conhecimento que se tem dela também, assim, não o tem. E isso, independente da formação dos sujeitos que estão atuando, enquanto especialistas, na abordagem e no ensino dessa temática.

A partir dessa observação, evidencia-se que a inserção da sustentabilidade nos Programas de Pós-Graduação Stricto Sensu em Administração vem ocorrendo, mas não em passos largos e nem com estratégias predefinidas a essa finalidade. Isso implica a observação de que, apesar da recomendação n. 02/2013 do Conselho Nacional de Educação (CNE) para se trabalhar a sustentabilidade nos Programas de Pós-Graduação, se não de maneira interdisciplinar, como conteúdo disciplinar, observa-se 
que tanto as linhas de pesquisa dos programas quanto suas áreas de concentração carecem, ainda, do comprometimento para com a inserção da temática nos conteúdos curriculares. Além disso, o conhecimento produzido pelos especialistas é, geralmente, desconectado das disciplinas as quais lecionam. O foco das disciplinas é mais direcionado às linhas de pesquisa e/ou áreas de concentração dos programas que, em maior parte, não são relacionados à temática.

Sendo a sustentabilidade, ainda, um tema com pouca inserção nos Programas Stricto Sensu, pode-se perceber, por meio desta pesquisa, que, de modo geral, quando essa inserção ocorre, ela acontece em todos os níveis de ensino, como apontado na seção 4.1. Entretanto, é importante lembrar que a experiência do professor, conforme apurado na análise quantitativa, não é significativa, também, para a sua percepção, ou a de seus alunos, quanto à preocupação de seus Programas para com a sustentabilidade. Mesmo porque, ainda se tratando das análises quantitativas, observou-se que o tempo de experiência do professor não é significativo, nem mesmo quanto ao seu próprio entendimento do que vem a ser a sustentabilidade ou a sua preocupação com a temática ou sua inserção das disciplinas ministradas.

\section{CONCLUSÃO}

A ausência de contornos conceituais para o tema faz com que sua inserção, nas diversas e diferentes esferas sociais, aqui com especificidade aos Programas Stricto Sensu em Administração, apresente-se de maneira difusa. Ou seja, um conjunto de valores e significações associado à racionalidade moderna e que, por isso mesmo, pode ser apenas intuída e associada aos padrões clássicos de se desenvolver uma sociedade. Logo, pode-se concluir que a inserção da sustentabilidade nos Programas Stricto Sensu em Administração vem ocorrendo, mas esta ainda não possui um entendimento pleno e único por parte dos especialistas, sendo seu tratamento, em razão disso, orientado por pesquisadores que buscam o seu entendimento de maneira isolada.

O entendimento do valor e das questões que envolvem a sustentabilidade e sua inserção nos Programas de Pós-Graduação Stricto Sensu em Administração, atualmente, somente pode ser percebido por meio de uma construção científica, realizada por meio da sistematização de sinais que, aos olhos dos mais leigos ou no senso comum, passam despercebidos.

O desafio da inserção de um novo olhar proposto pela sustentabilidade ainda não está sendo enfrentado de maneira efetiva pelos Programas. Mas esse feito não ocorre porque não se busca e/ou se tenta alinhar o foco da pesquisa à sustentabilidade. Ao contrário ocorre somente porque não se sabe ainda, de maneira clara, como fazê- 
-lo. Em outras palavras: a sustentabilidade se revela não como um conceito, mas como uma categoria de análise, ainda fractal, de múltiplas possibilidades e, em decorrência disso, sem contornos e entendimentos definidos.

Ao que tudo indica, os desafios impostos pela sustentabilidade de um desenvolvimento não atrelado, necessariamente, ao crescimento econômico, a diminuição da miséria, a busca de padrões sustentáveis de produção e consumo, entre outros, traduz-se como um novo olhar que impõe, aos Programas de Pós-Graduação em Administração, a necessidade de se (re)pensar seus currículos sob um novo olhar; carece, ainda, de melhor entendimento e de uma sólida matriz conceitual para ser enfrentado. Enfrentamento esse que, sendo urgente, parece ser o principal fio condutor para as mudanças nos valores éticos e morais dos indivíduos por meio da construção e disseminação do conhecimento que, por meio desses Programas, poderão ser refletidos em toda a sociedade.

Utilizando-se dos dizeres de Marcomim e Silva (2009), quando se referem às universidades, os Programas de Pós-Graduação em Administração enfrentam, no Brasil, a ausência de respaldo dos principais tomadores de decisões, e a quase ausência de políticas públicas integradoras de educação e sustentabilidade. Isso ocorre porque, ainda hoje, a estrutura organizacional e curricular não é capaz de refletir as mudanças inerentes à sociedade, implicando, decorrência disso, resistência ao tratamento da temática, configurando um desafio para uma efetiva inserção do tema nos programas de pós-graduação em Administração.

A pesquisa aqui desenvolvida contou com a participação de especialistas em sustentabilidade, integrados a programas de Pós-Graduação Stricto Sensu em Administração, independente de sua linha ou grupo de pesquisa. Em decorrência disso, coloca-se como sugestão de pesquisas futuras a realização desse trabalho em outras áreas de conhecimento, como as ciências exatas ou as ciências humanas, para que seus resultados, ao serem comparados com o aqui exposto, possam delinear diretrizes para um possível entendimento mais abrangente acerca da inserção da sustentabilidade nos Programas de Pós-Graduação Stricto Sensu no Brasil.

\section{REFERÊNCIAS}

ABRAMOVAY, R. Muito além da economia verde. São Paulo: Abril, 2012.

ADOMSSENT, M. et al. Emerging areas in research on higher education for sustainable development and management education, sustainable consumption and perspectives from Central and Eastern Europe. Journal of Cleaner Production, v. 62, p. 1-7, 2014. 
BALBACHEVSKY, E. A. Pós-Graduação no Brasil: novos desafios para uma política bem-sucedida. In: BROCK, C.; SCHWARTZMAN, S. (Org.). Os desafios da educação no Brasil. Rio de Janeiro: Nova Fronteira, 2005.

BERTERO, C. O. Teses em Mestrados Profissionais. Revista de Administração Contemporânea, v. 2, n. 1, p. 165-172, 1998.

BERTERO, C. O.; CALDAS, M. P.; WOOD JÚNIOR, T. (Org.). Produção científica em administração no Brasil: o estado da arte. São Paulo: Atlas, 2006.

BERTERO, C. O.; CALDAS, M. P.; WOOD JÚNIOR, T. Produção científica em administração de empresas: provocações, insinuações e contribuições para um debate local. Revista de Administração Contemporânea, v. 3, n. 1, p. 147-178, 1999.

BOYD JÚNIOR, H. W.; WESTFALL, R. Pesquisa mercadológica: textos e casos. 4. ed. Rio de Janeiro: Ed. FGV, 1979.

BARTH, M. et al. Developing key competencies for sustainable development in higher education. International Journal of Sustainability in Higher Education, v. 8, i. 4, p. 416-430, 2007.

BRUNDIERS, K.; WIEK, A.; REDMAN, C. L. Real-world learning opportunities in sustainability: from classroom into the real world. International Journal of Sustainability in Higher Education, v. 11, i. 4, p. 308-324, 2010.

CANHADA, D. I. D.; BULGACOV, S. Práticas sociais estratégicas e resultados acadêmicos: o doutorado em Administração na USP e na UFRGS. Revista de Administração Pública, v. 45, n. 1, p. 7-32, 2011.

CARROL, A. B. Corporate social responsibility. Business and Society, v. 38, i. 3, p. 268-295, 1999.

COOPER, D. R.; SCHINDLER, P. S. Métodos de Pesquisa em Administração. 7. ed. São Paulo: Bookman, 2003.

COORDENAÇÃO DE APERFEIÇOAMENTO DE PESSOAL DE NÍVEL SUPERIOR. Documentos de Área. Área de Avaliação: Administração, Ciências Contábeis e Turismo. CAPES, 2013a. Disponível em: <http://www.capes.gov.br>. Acesso em: 03 maio 2013. 
COORDENAÇÃO DE APERFEIÇOAMENTO DE PESSOAL DE NÍVEL SUPERIOR. Fichas de Avaliação do Programa. Programas de Pós-Graduação em Administração. CAPES, 2013b. Disponível em: <http://www.capes.gov.br>. Acesso em: 04 maio 2013.

COORDENAÇÃO DE APERFEIÇOAMENTO DE PESSOAL DE NÍVEL SUPERIOR. Linhas de Pesquisa: Visão Geral, Evolução e Tendências. Memória da Pós-Graduação. CAPES, 2013c. Disponível em: <http://www.capes.gov.br>. Acesso em: 28 abr. 2013.

COORDENAÇÃO DE APERFEIÇOAMENTO DE PESSOAL DE NÍVEL SUPERIOR. Reformulação do Sistema de Avaliação da Pós-Graduação: O Modelo a ser implantado na Avaliação de 1998, 1996. CAPES, 2013d. Disponível em: <http:// www.capes.gov.br>. Acesso em: 28 abr. 2013.

FIELD, A. Descobrindo a Estatística usando O SPSS. Porto Alegre: Armed, 2009.

FLYNN, B. B. et al. Empirical Research Methods in Operations Management. Journal of Operations Management, v. 9, i. 2, 1990.

GLOBAL FOOTPRINT NETWORK. The Living Planet Report 2010. Disponível em: <http://www.footprintnetwork.org/en/index.php/GFN/page/living_planet_report_2010>. Acesso em: 02 fev. 2011.

GOMES, A.; MORETTI, S. L. A. A Responsabilidade e o Social: uma discussão sobre o papel das empresas. São Paulo: Saraiva, 2007.

GONÇALVES-DIAS, S. L. F.; BELLOQUE, M.; HERRERA, C. B. Desafios para inserção da disciplina "sustentabilidade" em cursos de Administração: a experiência de uma Instituição de Ensino Superior paulistana. Disponível em: <http:// www.ead.fea.usp.br/semead/14semead/resultado/trabalhosPDF/851.pdf $>$. Acesso em: 12 nov. 2012.

GRACIAREMA, J. Pós-Graduação em ciências sociais na América Latina. Revista Brasileira de Estudos Pedagógicos, Brasília, DF, v. 58, n. 128, p. 265-280, 1972.

HAMBURGER, E. Para que Pós-Graduação? Encontros com a civilização brasileira. Rio de Janeiro: Civilização Brasileira, 1980.

HART, S. L. Capitalism at the Crossroads. 2nd ed. Upper Saddle River: Wharton School Publishing, 2007. 
HART, S. L.; MILSTEIN, M. B. Creating Sustainable Value. Academy Of Management Executive, v. 17, i. 2, p. 56-67, 2003.

JACOBI, P. R.; RAUFFLET, E.; ARRUDA, M. P. de. Educação para a sustentabilidade nos cursos de administração: Reflexão sobre paradigmas e práticas. RAM Revista de Administração Mackenzie, v. 12, n. 3, p. 21-50, 2011.

LEAL FILHO, W. About the role of universities and their contribution to sustainable development. Higher Education Policy, v. 24, p. 427-438, 2011.

LIMA, J. B. Temas de pesquisa e desafios da produção científica sobre PME. Revista de Estudos Organizacionais, Maringá, v. 1, n. 2, p. 27-47, 2000.

MACHADO, A. M. N.; ALVES, V. M. Recuperando origens e trajetórias do sistema de Pós-Graduação brasileiro em educação. Unirevista, v. 1, n. 2, abr. 2006.

MALHOTRA, N. Pesquisa de marketing: uma orientação aplicada. 4. ed. Porto Alegre: Bookman, 2006.

MARCOMIN, F. E.; SILVA, A. D. V. A sustentabilidade no ensino superior brasileiro: alguns elementos a partir da prática de educação ambiental na universidade.

Contrapontos, v. 9, n. 1, p. 173-190, 2009.

MENDONÇA, A. W. P. C. A Pós-Graduação como estratégia de reconstrução da universidade brasileira. Educar em revista, Curitiba: Ed. UFPR, v. 21, n. 1, p. 289308, 2003.

MIRANDA, M. M. S.; MORESI, E. A. D. A gestão do conhecimento no compartilhamento de melhores práticas em uma base de dados no Tribunal Regional Federal da Primeira Região. Jistem J.Inf.Syst. Technol. Manag., São Paulo, v. 7, n. 2, 2010. Disponível em: <Http://www.scielo.br/scielo.php?script=Sci_Arttext\&Pid=S1807-17752010000200008\&Lng =En\&Nrm=Iso>. Acesso em: 06 dez. 2013.

MORETTI, S. L. D. A.; FIGUEIREDO, J. C. Análise bibliométrica da produção sobre responsabilidade social das empresas no Enanpad: Evidências de um discurso monológico. Revista de Gestão Social e Ambiental, v. 1, n. 1, p. 21-38, 2007. 
PEREIRA, R. C. F. et al. Doutorado em administração no Brasil: um estudo exploratório dos fatores relacionados ao conceito de doutor e das responsabilidades dos principais agentes envolvidos no curso de doutorado. In: ENCONTRO NACIONAL DE PESQUISA E PÓS-GRADUAÇÃO EM ADMINISTRAÇÃO, 2002, Salvador. Anais... Salvador: Anpad, 2002.

PETARNELLA, L.; HOURNEAUX JUNIOR, F.; SILVEIRA, A. A inserção da sustentabilidade nos Programas de Pós-graduação Stricto Sensu em Administração sob a ótica dos especialistas. In: SEMINÁRIOS EM ADMINISTRAÇÃO, 27., 2014, São Paulo. Anais... São Paulo: Semead, 2014.

PETARNELLA, L.; SILVEIRA, A. Ensino e pesquisa em administração: um novo olhar sobre a sustentabilidade. In: SEMINÁRIOS EM ADMINISTRAÇÃO, 26., 2013, São Paulo. Anais... São Paulo, 2013.

PETARNELLA, L.; SILVEIRA, A. Pensamento reflexivo e formação acadêmica em sustentabilidade: os Programas de Pós-graduação Stricto Sensu em Administração. In: ENCONTRO NACIONAL DE PESQUISA EM ADMINISTRAÇÃO, 2014, Rio de Janeiro. Anais... Rio de Janeiro, 2014.

PIRSCH, J.; GUPTA, S.; GRAU, S. L. A Framework for understanding corporate social responsibility programs as a continuum: an exploratory study. Journal of Business Ethics, v. 7, i. 1, p. 125-140, 2007.

ROSSI, F. M. Writing in an advanced undergraduate chemistry course: an assignment exploring the development of scientific ideas. Journal of Chemical Education, v. 74, i. 1, p. 395-396, 1997.

SACHS, I. Desenvolvimento: includente, sustentável, sustentado. Rio de Janeiro: Garamond, 2004.

SAMPIERI, R. H.; COLLADO, C. F.; LUCIO, P. B. Metodología de la investigación. México: Mcgraw Hill, 2003.

SANTOS, C. M. Tradições e contradições da pós-graduação no Brasil. Educação e Sociedade, v. 24, n. 83, p. 627-641, 2003.

SAUNDERS, M.; LEWIS, P.; THORNHILL, A. Research Methods for Business Students. 4th ed. Harlow: Pearson Education Limited, 2007. 
VIEDERMAN, S. The Economics of Sustainability: challenges. Recife: Fundação Joaquim Nabuco, 1994.

Como citar este artigo:

ABNT:

PETARNELLA, Leandro; JUNIOR, Flavio Hourneaux; SILVEIRA, Amélia. A inserção da sustentabilidade nos programas de Pós-graduação stricto sensu em Administração: a ótica dos especialistas. RACE: Revista de Administração, Contabilidade e Economia, Joaçaba: Ed. Unoesc, v. 15, n. 1, p. 227-250, jan./abr. 2016. Disponível em: <http://editora.unoesc.edu.br/index.php/race>. Acesso em: dia/mês/ano.

\section{APA:}

Petarnella, L., Junior, F. H., \& Silveira, A. (2016). A inserção da sustentabilidade nos programas de Pós-graduação stricto sensu em Administração: a ótica dos especialistas. RACE: Revista de Administração, Contabilidade e Economia, 15(1), 227-250. Recuperado em dia/mês/ano, de http://editora.unoesc.edu.br/index.php/race 
